\title{
Rights and Strikes in Healthcare
}

The bioethics literature on collective labor protest actions by health professionals is modest and recent, focusing almost exclusively on strike actionsalthough that is beginning to change. The essays in this special section of the Cambridge Quarterly seek to further explore many of the key ethical issues in some detail. The authors analyze existing ethical tensions and propose responses (none presume to call them solutions) to the increasingly hostile conflicts between licensed health professionals and the new corporate management of healthcare organizations.

As a healthcare ethics consultant and philosopher, I provide a brief overview of several key features of modern healthcare organizations in the United States that contribute to feelings by care providers that collective protest actions are needed, perhaps even morally required. I discuss changes in the delivery of services, the compensation arrangements of physicians, and the financing of patient care as brought about by dramatic organizational changes involving large corporations and the changing characteristics of health system leadership. I then discuss several ways in which patients' healthcare needs and services have changed over the past 30 years and how that has contributed to the fractionalization of health professionals' hierarchy of authority. Finally, I discuss the ethical requirements for collective protest actions in terms of the health professionals' duties to both self and to patients and I suggest ways in which protest actions may be supported by nonprotesting workers without significant loss of the safety or welfare of patients for limited periods of time.

Surgeon and ethicist Sunil Pandya discusses the unique employment circumstances of medical residents in India, whom he reports must engage in strike actions every few years to protest the below-subsistence wages they earn in the large government-run teaching hospitals. As both a faculty surgeon and editor of India's largest medical ethics journal, Dr. Pandya is deeply troubled by these strike actions that place the residents in both a financially hopeless and an ethically unacceptable position. But he also worries that the best ethical response by faculty physicians is neither clear nor always aimed at serving the best interests of their own patients.

In a companion piece to the article by Pandya, Susan Braithwaite argues that strike actions are never ethically permissible for purposes of personal gain and will always require for legitimacy a focus on issues related primarily to the interests of patients and their welfare. She notes that the ethical import of the risk to patients from loss of adequate care by striking physicians turns partially on the roles of the striking physicians. Strikes by interns and residents may be less blameworthy than strikes by attending physicians, because responsibility for the harm to 
patients falls at least partially on the faculty's prior administrative decisions to accept more patients than can be properly cared for without the residents. Braithwaite makes the important moral point that it is the hospitaland not the physicians employed there-that has assured the local community of the availability of medical services. Thus, residents may be the only physicians who can ethically justify collective withdrawal of patient care services, for their circumstances are measurably worse and their responsibility for the effects on patients legally more limited than that of their instructors who are duty-bound to ignore residents' strike barriers and to provide services. Alternative protest actions that fall short of strikes are, according to Braithwaite, ethically permissible for physicians who have strong disagreements with managers concerning patient care service delivery systems.

Philosopher Ruth Chadwick teaches healthcare ethics in England. She and her former graduate researcher Alison Thompson, now based in Toronto, provide a look at the historical development of the relative power positions of physicians and nurses in securing adequate working conditions in the United Kingdom, and what role the ideal of service has played in generating those positions. Within that historical framework, they discuss the ethical permissibility of engaging in several kinds of industrial action, including strikes, examining how recent changes in the core values of professionalism may affect the likelihood of future industrial actions. Chadwick and Thompson agree with most commentators that strike actions aimed at increasing compensation to strikers are permissible if and only if the economic conditions are negatively affecting patient care, and they argue that strike actions should always be efforts of the last resort, following only after the failure of all other attempts. They find the relative power differences between nurses and physicians (grounded principally in issues of gender) to have significant ethical import. They suggest that nurses' strikes may be more easily permitted from an ethical point of view because nurses have been so poorly treated generally. They argue for many of the same minimum requirements others have stipulated for ethically permissible industrial actions, including the maintenance of emergency services and the need for generating broad public support. These authors make the often overlooked point that although the harms occurring to patients with and without industrial action (i.e., under strike conditions vs. the current inadequate conditions) may be morally equivalent, the side effects of the harms occurring are different, and therein may reside an important ethical difference.

Physician-ethicist Susan Dorr Goold's essay focuses on the specific form of trust that physicians traditionally have been granted by the public, and discusses how that trust generates the ethical obligation to provide essential services under virtually all conditions. Beyond essential services, however, collective protest actions can be ethically defended if the motivation is a just and fair wage for professionals, or if their accountability for patient welfare exceeds the protections needed to assure their professional autonomy.

Philosopher Rodger L. Jackson provides a careful and in-depth discussion of the philosophical nature of both trust and betrayal, showing how they are related to each other and to goodwill. His analysis places collective protest actions within a larger philosophical context with the intent that future protests can then be effectively evaluated. The evaluation turns, according to Jackson, on whether the protest actions support or destroy professionals' integrity re- 
garding their obligations of patient trust and avoidance of betrayal.

Physician-ethicist Erich Loewy contributes an essay aimed at understanding the social and political implications of denying collective protest actions, especially strikes, to any workers, including those who provide healthcare and other essential services. Loewy's theme focuses on the consequences to workers who must endure oppressive working conditions but who lack adequate resources with which to improve those conditions. In direct opposition to the new AMA position concerning strikes, Loewy concludes that, as a matter of political justice, all workers must be guaranteed the right to strike to avoid becoming enslaved by their employers. The conditions under which such a right may be exercised ethically vary in regard to four distinct concerns: the nature of the work, the prior commitment of the striking worker to the person(s) most directly affected by the strike action, the particular circumstances of the strike action, and the persons the strike action is intended to benefit. Loewy argues that although strikes by their nature are always class struggles, a direct market analysis of them would be inappropriately applied to the healthcare arena. As healthcare organization and financing structures evolve in the United States, the fiduciary concerns traditionally held by physicians toward their patients tend to shift more toward the physicians' employers, which increasingly are large corporate organizations. The moral landscape of responsibility and accountability becomes thereby altered in very important ways. 